\title{
ENVELHECIMENTO POPULACIONAL, FEMINIZAÇÃO DA VELHICE E SAÚDE: algumas dimensões de análise*
}

\author{
Rita de Cássia Santos Freitas \\ Adriana de Andrade Mesquita
}

\begin{abstract}
Sei que tenho muitos anos. Sei que venho do século passado, e que trago comigo todas as idades, mas não sei se sou velha, não. Você acha que eu sou? (...) Sei que alguém vai ter que me enterrar, mas eu não vou fazer isso comigo (Cora Coralina ${ }^{1}$ ).
\end{abstract}

\section{Introdução}

O envelhecimento populacional tem se apresentado como um dos grandes desafios da atualidade, pois, ao mesmo tempo, em que o aumento da longevidade tem se dado como uma realidade em diversos países ao redor do mundo, também apresenta limites e desafios nessas mesmas sociedades. $\mathrm{O}$ envelhecimento mundial vem ocorrendo de forma rápida e intensa, o que traz questões a serem consideradas no que se refere à saúde pública em países de capitalismo dependente, como é o caso brasileiro.

O processo de envelhecimento populacional se tornou uma das características marcantes da dinâmica demográfica mundial. A Organização das Nações Unidas (ONU), em 17 de junho de 2019, publicou o World Population Prospects (2019), que demonstra as novas projeções populacionais em todos os países ${ }^{2}$. Segundo o documento, em meados do século XX, o envelhecimento populacional é uma realidade que se apresentava de forma lenta e gradual, ao longo do século XX, mas que se acelerou em inícios do século XXI. Conforme o referido estudo, o número de pessoas acima de 60 anos deverá seguir a seguinte projeção: em 1950, a população mundial era acima de 345 milhões pessoas; em 2000, esse número passou para 1,1 bilhão; em 2050, deverá passar para mais de 4 bilhões de habitantes; e, em 2100, alcançará a média de 3,1 bilhões de pessoas no mundo. Em todos os anos apresentados o maior crescimento se dará com pessoas entre 60 e 64 anos de idade. O caso brasileiro não é muito diferente da tendência global; ao contrário disso, o envelhecimento populacional brasileiro é ainda mais rápido ${ }^{3}$. Todos esses dados mostram que o envelhecimento populacional é um fato irreversível. Importante sinalizar que o estudo apresentado pela ONU foi no ano de 2019, anterior ao contexto mundial de pandemia gerada pelo novo coronavírus (que se expandiu em esfera mundial a partir de fevereiro de 2020), em que as condições de vida das pessoas mais velhas estão sendo duramente afetadas. Estudos epidemiológicos ${ }^{4}$ têm demostrado que as pessoas mais velhas e aquelas com doenças crônicas preexistentes são mais acometidas pelo vírus, tornando-se as principais vítimas graves ou de óbitos por COVID-19. Isso acabou por reforçar no debate político e acadêmico a priorização das pessoas mais velhas no que se refere a efetivação de

\footnotetext{
*DOI- 10.29388/978-65-81417-27-7-0-f.109-127

${ }^{1}$ https://piorambo.blogspot.com/2011/11/sobre-velhice-linda-mensagem-de-cora.html\#.YFSBBa_7TMw. Acessado em 19/03/2021.

2 Acessar publicação no link: https://population.un.org/wpp/Publications/Files/WPP2019_Highlights.pdf

${ }^{3}$ Discutiremos os dados do Brasil mais a frente, na terceira parte desse capítulo.

${ }^{4}$ Ver, por exemolo: CORREIA, M. \& JUSTO, J. Pandemia e envelhecimento. Revista Espaço Acadêmico - Edição Especial. Ano XX, 2021.
} 
medidas de proteção e de prevenção frente ao vírus. Neste sentido, a pandemia intensificou uma conjuntura que já era complexa.

Contamos na atualidade com um considerável arcabouço político de proteção social à esse segmento populacional, como falaremos melhor adiante. São dispositivos, fruto das lutas desses diferentes sujeitos que tem por objetivo promover a autonomia, integração e participação desses na sociedade de forma plena. Neste capítulo, nos voltamos para uma dimensão essencial dessas políticas: pensamos na saúde das pessoas idosas, especialmente, na saúde das mulheres idosas. E, para evitar controvérsia, dizemos de antemão que utilizamos aqui idosos e velhos como sinônimos, sem adentrar numa discussão mais ampla sobre esses conceitos.

Discutir a relação entre idosas ${ }^{5}$ e saúde é o objetivo desse texto que não tem, é claro, a pretensão de esgotar a temática em estudo, principalmente se considerarmos que esta é uma de nossas primeiras aproximações a esse tema - mas aceitamos aqui o desafio de tecer algumas contribuições em relação à essa temática. Mais especificamente temos como objetivo principal refletir acerca do processo de envelhecimento da população brasileira - dando visibilidade ao processo de feminização da velhice - e de seus rebatimentos na saúde pública ${ }^{6}$, a partir de um olhar feminista e interseccional. Esse é o diferencial que buscamos trazer neste texto. Atendemos idosas e idosos que chegam aos nossos plantões. Mas como as/os vemos? O que se esconde por trás dessa categoria abstrata, "idosas"/“idosos”? quem são essas/es sujeitas/os? É sobre isso que queremos falar. Entendemos que o acesso, com qualidade, aos serviços de saúde por parte da população idosa, em especial entre os seguimentos mais vulnerabilizados, sempre foi uma questão a ser debatida e que se agrava no atual cenário pandêmico, como dito antes.

A poesia muito nos ensina. Cora Coralina, nossa poeta do século passado, nos convida à reflexão. Quando sabemos que estamos velhas? Apenas o corpo decide a chegada da velhice? Os cabelos embranquecidos são sinais que envelhecemos? E, quando a nossa mente não se sente velha? quando, pelo contrário, ela sente que avançou, que sabe mais e entende que deveria poder fazer mais exatamente por isso? O que fazer quando o corpo não acompanha a mente? Como as representações que os outros tem de nós impactam também na forma nos vemos?

A visão da velhice como sabedoria nos abandonou nessa sociedade do capital, onde a juventude é a moeda de troca. Ao contrário disso, a velhice passou a ser sinônimo de impedimentos, de coisas negativas e de infantilização da/o idosa/o. Mas como nos diz Cora, "alguém vai ter que me enterrar, mas eu não vou fazer isso comigo". E nós? Como lidamos com nossas/os velhas e velhos? Estamos as/os enterrando antecipadamente? As/os vemos como pessoas inúteis em nossa sociedade? Ou conseguimos respeitá-las/os em suas pluralidades e desejos? Enquanto sujeitos de direitos? É muito comum a tendência à infantilização da velhice, a vê-la de forma homogênea (permeada por doenças crônicas, perdas sociais, afetivas e financeiras). Contudo, é latente compreender a velhice de forma não homogênea (LINS E ANDRADE, 2018) e complexificar esta categoria. O processo de envelhecimento não acontece da mesma forma entre os diferentes sujeitos e temos como entendimento que o fato de uma pessoa ser maior de 60 anos não a transforma necessariamente em um "sujeito único de direitos", como apontam Lins e Andrade (2018). Mulheres e homens não envelhecessem da mesma forma, pois

\footnotetext{
${ }^{5}$ Vamos colocar idosas no feminino por entendermos que esse público é majoritariamente composto por mulheres. Trata-se de iniciativa, baseada numa epistemologia feminista (KETZER, 2017; LOURO, 1997) e tem por objetivo dar visibilidade às mulheres.

6 Área que, historicamente, é importante espaço de trabalho para as assistentes sociais (MORAES, SANTOS e GONÇALVES, 2020). Da mesma forma, também utilizamos assistentes sociais no feminino por entender que essa categoria profissional é composta majoritariamente por mulheres (assim como a população que atende).
} 
as condições de gênero, raça/etnia, classe e territorialidade (entre outras) impactam nesse processo.

Envelhecer não é uma realidade única, por isso, a importância da abordagem interseccional (que discutiremos melhor mais adiante) para buscar compreender a forma como os diversos marcadores sociais atuam sobre esse processo. Gênero, classe social, raça-etnia, territorialidade, deficiências são algumas dimensões que podemos destacar para compreender o processo de envelhecimento. Enfim, o que estamos tentando dizer é que essas pessoas precisam ser conhecidas - e ouvidas - para que possamos compreender suas demandas e desejos e não falar por elas, por acharmos que sabemos o que "é melhor" para elas.

A organização do presente capítulo se deu da seguinte forma: em primeiro lugar, buscamos discutir o envelhecimento numa visão feminista, descolonial e interseccional. Em seguida, analisamos o processo de envelhecimento populacional, no Brasil, a partir de dados quantitativos, dando ênfase ao processo de feminização do envelhecimento; e, em seguida, refletimos como esse processo repercute na área da saúde. Terminamos com algumas propostas para pensar a intervenção junto à essa população.

\section{Envelhecimento numa visão feminista, descolonial e interseccional}

Realizar uma análise do envelhecimento da população brasileira numa perspectiva feminista, descolonial e interseccional é buscar problematizar esse processo de modo diferenciado, considerando as condições de gênero, raça/etnia, sexualidade e classe que perpassam esse segmento etário. É compreender esse processo em sua dinamicidade, pluralidade, diversidade, como um fato que marca o mundo de forma irreversível e que precisa ser melhor analisado a partir das condições específicas de nossa sociedade e das vidas vividas pelas pessoas. Como afirma Grada Kilomba (2020, p. 08): “descolonizar o conhecimento significa criar novas configurações de conhecimento e de poder (...) a teoria não é universal nem neutra, mas sempre localizada em algum lugar e sempre escrita por alguém, e que este alguém tem uma história" (KILOMBA, 2020, p. 8). Por isso, abordar a perspectiva descolonial significa a recusa a um conhecimento eurocêntrico, tido como o único válido e que reforça a dominação cultural.

A apropriação do pensamento descolonial ${ }^{7}$ vai no sentido de considerar as vivências experimentadas na sociedade brasileira, sem perder de vista a historicidade deste processo histórico, marcado pelo colonialismo, o sexismo, o patriarcado, o racismo e a escravidão. Em relação ao nosso tema, significa pensar os limites e desafios vivenciados por parte da população mais velha - especialmente as mulheres - que precisam ser superados.

A análise numa perspectiva feminista busca compreender e transformar as desigualdades de gênero na sociedade. Tal perspectiva resulta numa epistemologia feminista que pode, resumidamente, ser descrita como uma crítica às categorias universais (como a Mulher, o Homem); o rompimento com hierarquias, sendo um conhecimento libertário e emancipador (por isso, sua preocupação com a justiça social) que incorpora a dimensão do subjetivo e uma nova relação teoria-prática por colocar no centro a relação dos diferentes sujeitos no mundo. É um conhecimento necessariamente interdisciplinar (e indisciplinar - SANTOS, 2006) onde as mulheres são sujeitos do conhecimento (RAGO, 2019; LOURO, 1997; KETZER, 2017).

\footnotetext{
${ }^{7}$ Ver, neste sentido, Curiel (2020) para problematizar o feminismo descolonial.
} 
A noção de interseccionalidade, contribuição imprescindível do feminismo negro, (CRESNSHAW, 2002; COLLINS, 2015; CARNEIRO, 2003) critica a visão essencializada da Mulher $^{8}$. A interseccionalidade ${ }^{9}$ nos ajuda a pensar esse sujeito que envelhece, pois envolve elementos identitários, de raça/etnia, classe, sexualidade, território, geração, entre outros. A questão racial impacta na forma como mulheres e homens envelhecem, assim como a classe determina o tipo de acesso aos serviços de saúde, equipamentos sociais, informação, etc. O local de moradia, igualmente, favorece ou não o acesso a esses equipamentos e a uma vida mais segura.

Deste modo, é essencial pontuar que não nos vinculamos a uma perspectiva teórica que privilegia apenas três eixos: classe social, gênero e raça (MEDEIROS e FREITAS, 2017). A interseccionalidade é promissora ferramenta analítica por permitir a apreensão de outras relações como sexualidade, idade, religião, territorialidades e deficiências - que não podem, em nossa opinião, serem hierarquizadas. Para Patrícia Collins (2015), a interseccionalidade é uma das formas de combater as opressões múltiplas e imbricadas, logo é um potente instrumento de luta política $^{10}$.

As particularidades do envelhecimento brasileiro devem ser pensadas interseccionalmente numa relação direta com os estudos de gênero, categoria fundamental de análise trazida pelos movimentos feministas e de mulheres (LOURO, 1997; SCOTT 1991; 2012). A categoria gênero deve ser entendida de forma relacional enquanto uma construção histórica das feminilidades e das masculinidades nas diversas sociedades e trazendo embutido em si uma relação de poder (SCOTT, 1991). Fruto das relações diretas entre o feminismo e as feministas acadêmicas, a categoria gênero nos é cara por enfatizar a dimensão social das relações entre homens e mulheres. Mas pode ser complexificada ao abordar tanto a crítica do feminismo negro, como do lésbico ou do transfeminismo. O que buscamos enfatizar aqui é que os estudos de gênero e interseccionalidade são indispensáveis para se problematizar o lugar que as mulheres idosas desempenham na sociedade brasileira, bem como as particularidades desse processo. As discussões sobre as relações de gênero e raciais permitem "desnaturalizar" e "historicizar" as desigualdades que existem entre homens e mulheres. E, no caso desse estudo, as desigualdades entre idosas e idosos. Tais considerações nos exige a conjecturar gênero para além da heteronormatividade que caracteriza nossa sociedade e nos possibilita pensar as particularidades da população LGBTQIA+, em especial, as lésbicas, travestis e mulheres trans que também envelhecem (LAHNI, 2019). As questões das mulheres negras, lésbicas, latinas e não ocidentais precisam ser repensadas para além de uma epistemologia branca, europeia, heterocentrada e falocêntrica.

Para conhecer esses sujeitos é igualmente necessário atentar para o estudo da dimensão racial. Os dados apontam que as mulheres vivem mais do que os homens. Mas não podemos esquecer que são os homens negros e pobres que mais vem morrendo em nossa sociedade. $\mathrm{Na}$ verdade, os homens têm chegado menos a uma maior idade e isso não se deve apenas aos problemas de saúde. Homens negros são executados nessa sociedade onde são vistos como

\footnotetext{
8 Ver, neste sentido, Oyěwùmí (2004).

9 A interseccionalidade "trata especificamente da forma pela qual o racismo, o patriarcalismo, a opressão de classe e outros sistemas discriminatórios criam desigualdades básicas que estruturam as posições relativas de mulheres, raças, etnias, classes e outras (CRENSHAW, 2002, p. 177 - grifos nossos).

10 Santos (2006) traz a definição de intersecionalidade da Association for Women's Rights in Development (AWID): “ferramenta de análise, militância e desenvolvimento de políticas que considera a discriminação múltipla e nos ajuda a compreender o impacto de diferentes eixos identitários no acesso a direitos e oportunidades” (AWID, 2004: 12 apud SANTOS, 2006).
} 
dispensáveis, nessa necropolítica (MBEMBE, 2018) que vem caracterizando os tempos atuais e que é resultado do racismo estrutural que perpassa a sociedade. Como afirma Almeida (2017, p. 43), "em uma sociedade racializada e fortemente marcada pela tradição colonial, o racismo opera, dentre outras formas, para destituir sua vítima da condição humana". A saúde física e mental da população negra é condicionada por determinantes sociais onde o "desgaste físico, as humilhações, o preconceito e discriminações farão parte da vivência negra" - ainda que essas violências não tenham se dado sem resistências (ALMEIDA, 2017).

Da mesma forma, não podemos esquecer que envelhecer não possui o mesmo significado se pensarmos em termos de classe social. O envelhecer traz gastos, a economia do cuidado nos demonstra como o cuidado de si é uma atividade que congrega muito trabalho e a situação de classe impacta no acesso a esses cuidados e na forma como esse cuidado foi se estabelecendo ao longo da vida. Igualmente podemos pensar na questão da diversidade sexual: quem são os idosos que envelhecem? Quantas travestis, por exemplo, chegam a envelhecer? Essas são questões que não podemos perder de vista - ainda que nesse capítulo, a gente vá se concentrar no envelhecimento feminino. Somos levadas a pensar com Motta (2002) que as referências (negativas) ao envelhecimento e ao corpo são, ainda mais diretamente dirigidas às mulheres - e isso não se dá apenas porque vivem mais do que os homens, mas porque o corpo das mulheres sempre foi mais visado.

As mulheres sempre foram, tradicionalmente, avaliadas pela aparência física e pela capacidade reprodutiva. Em suma, pelo estado do seu corpo: pela beleza que possa exercer atração, pela saúde que permita reproduzir, pela docilidade de um corpo que se deixe moldar para tudo isso e também pela domesticidade, objeto permanente de gestão social (MOTTA, 2002, p. 45).

A maioria dos trabalhos se refere ao envelhecimento entre homens e mulheres da mesma forma, não levando em consideração suas características específicas. Findo esse item, vamos nos debruçar nos dados que vão nos deixar mais perto da realidade das idosas e idosos no Brasil.

\section{O envelhecimento populacional e a feminização da velhice no Brasil}

O processo de envelhecimento é um fato irreversível e se desenvolve de maneira diferenciada entre as diversas sociedades. Antes era um fenômeno que fazia parte de países desenvolvidos, agora se tornou uma realidade mundial. Com isso, indicadores sociais apontam mudanças nas estruturas demográficas, econômicas, sanitárias, entre outras. No Brasil, esse processo está ocorrendo de forma rápida e contínua e possui particularidades que precisam ser analisadas por ecoar no panorama mundial (MESQUITA et all; 2018).

De acordo com o relatório da ONU (2019), no Brasil, o número total de habitantes $x$ pessoas acima de 60 anos seguiu e deverá seguir a seguinte projeção: em 1950, a população brasileira era superior a 53 milhões, sendo 4.3 milhões de pessoas acima de 60 anos; em 2000, eram mais de 174 milhões de brasileiros e acima de 24 milhões de pessoas com mais de 60 anos; em 2020, a população chegou em cerca de 212 milhões de habitantes e mais de 54 milhões de pessoas acima de 60 anos; em 2050, prevê-se que a população nacional deve passar os 228 milhões de habitantes e ter aproximadamente 134 milhões de idosos. 
Tabela 1 - População absoluta de idosos (acima de 60 anos) no Brasil

\begin{tabular}{c|c|c|c|c}
\hline Anos & Total & $\begin{array}{c}\text { Pessoas de 60 } \\
\text { anos a 64 } \\
\text { anos }\end{array}$ & $\begin{array}{c}\text { Pessoas de } \\
\text { 65 anos a 79 } \\
\text { anos }\end{array}$ & $\begin{array}{c}\text { Pessoas } \\
\text { acima de } \\
80 \text { anos }\end{array}$ \\
\hline 1950 & 53.975 & 2.627 & 1.606 & 153 \\
\hline 2000 & 174.790 & 13.974 & 9.175 & 1.429 \\
\hline 2020 & 212.559 & 29.857 & 20.389 & 4.159 \\
\hline 2050 & 228.980 & 67.361 & 52.026 & 15.376 \\
\hline
\end{tabular}

Fonte: World Population Prospects 2019

Como se pode verificar, o número de idosos continuará crescendo e, com isso, novos limites e desafios se colocam para a sociedade brasileira. Diversos fatores estão contribuindo para isso como a queda da taxa de mortalidade, avanços da saúde preventiva (vacinas, antibióticos, quimioterápicos, etc.), novas tecnologias, melhoria nutricional, higiene pessoal e ambiental (NERI, 2001; SALGADO, 2002; NICODEMO \& GODOI, 2010; ALMEIDA et all 2015). Ou seja, é proeminente entender que a sociedade brasileira passa por grandes transformações e o processo de envelhecimento está se dando numa grande velocidade.

No ano de 2020, a população brasileira tinha mais de 221 milhões de habitantes, sendo composta por $48,9 \%$ de homens e 51,1\% de mulheres, processo esse conhecido como de feminização da sociedade brasileira. Essa diferença entre os sexos continua quando analisamos o processo de envelhecimento no país. Do total da população brasileira, em 2020, havia um total de $14,26 \%$ de pessoas idosas, sendo 7,97\% compostas por mulheres e $6,29 \%$ de homens. O maior percentual de idosos encontra-se na faixa etária entre 60 e 69 anos de idade. Ou seja, temos mais mulheres idosas do que homens idosos no país.

Gráfico 1 - Pirâmide Etária Brasil (2020 e 2050)
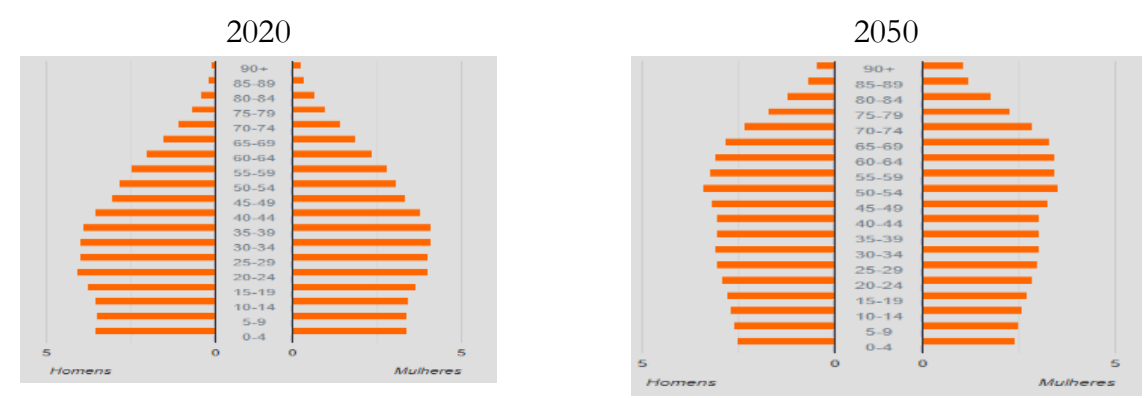

Fonte: IBGE Projeções (site www.ibge.gov.br/apps/populacao/projecao/).

Ao analisar comparativamente os gráficos acima, referentes aos anos de 2020 e 2050, é notório alterações na pirâmide etária brasileira, em que o número de crianças reduz e o número de pessoas acima de 60 anos aumenta expressivamente. As projeções para 2050 indicam que esse processo continuará pelas próximas décadas. O total de idosos passará dos 14,26\%, em 2020, para 28,46\%, em 2050. Praticamente, dobra-se o número de idosos em 30 anos no Brasil. E, deste total de idosos, em 2050, 15,89\% serão de mulheres idosas e 12,5\% de homens idosos. Em todos os seguimentos acima dos 60 anos, as mulheres continuarão em maior percentual, principalmente, entre 60 e 64 anos e 64 e 69 anos. Esse processo tem sido denominado de 
feminização da velhice por caracterizar a predominância de mulheres entre os idosos no Brasil ${ }^{11}$ : "pode-se assinalar, sem dúvida, que a velhice se feminilizou, converteu-se em um assunto de mulheres. O fato mais significativo e simples sobre a velhice é que a população idosa é predominantemente feminina" (SALGADO, 2002, p. 09).

Todavia, a feminização da velhice vem acompanhada de várias modificações sociodemográfico, médico-social e sociopsicológico que afetam diretamente o envelhecimento das idosas em sua vida cotidiana (NERI, 2001). Camarano et all (2004), ao analisarem o processo de envelhecimento populacional brasileiro, colocam que a heterogeneidade do envelhecimento feminino apresenta especificidades: "a heterogeneidade desse segmento extrapola a da composição etária. Dadas as diferentes trajetórias de vida experimentadas pelos idosos, eles têm inserções distintas na vida social e econômica do país" (2004, p. 25/26). Entre as questões sinalizadas nesse estudo, as mulheres idosas apresentam condição socioeconômica desvantajosa, já que a maioria das idosas de hoje não possuíram algum tipo de trabalho remunerado durante a fase de sua vida produtiva, tornando-se mais vulnerabilizadas financeiramente e, consequentemente, menos autônomas; o que se adensa se acrescentarmos a variável raça, uma vez que as famílias mais pobres em nossa sociedade são aquelas chefiadas por mulheres negras, caracterizando o processo de feminização da pobreza (FREITAS, BRAGA, BARROS, 2010).

Para melhor análise do processo de feminização da velhice, alguns indicadores de saúde devem ser levados em consideração, a saber: queda da fecundidade, aumento da esperança de vida e queda da taxa mortalidade. A taxa de fecundidade é uma estimativa do número de filhos por mulher em determinado país, região. A taxa de fecundidade brasileira está em constante declínio, conforme a tendência mundial, sobretudo dos países urbanizados. Como podemos observar na tabela abaixo, no ano de 1950 a taxa de fecundidade era de 6,21 filhos por mulher. A partir da década de 1960, passou por um processo de queda desta taxa, chegando, em 2020, a uma taxa de fecundidade de 1,76 .

Tabela 2 - Taxa de fecundidade Brasil

\begin{tabular}{c|c} 
Ano & Total \\
\hline 1950 & 6,21 \\
\hline 1960 & 6,3 \\
\hline 1970 & 5,8 \\
\hline 1980 & 4,4 \\
\hline 1991 & 2,9 \\
\hline 2000 & 2,3 \\
\hline 2020 & 1,76 \\
\hline 2050 & 1,68
\end{tabular}

Fonte: IBGE, Censo Demográfico de 2010 e IBGE Projeções

Nas palavras de Kalache (1987), a taxa de fecundidade é considerada fator determinante do envelhecimento em relação ao nível da população de um país. Alguns fatores levaram a esse declínio, tais como: a expansão da urbanização no meio rural, o avanço da medicina, a utilização de métodos contraceptivos (preservativos, diafragma, pílula anticoncepcional, etc.), a educação sexual, o planejamento familiar, o aumento participativo da mulher no mercado de trabalho e o

${ }^{11}$ Ver Salgado (2002), Nicodemo \& Godoi (2010); Almeida et all (2015); MESQUITA et all; 2018. 
aumento da escolaridade das mulheres. São aspectos relevantes que contribuem para redução da fecundidade no Brasil.

De outro lado, estamos presenciando o aumento da expectativa de vida no país. Esse indicador faz relação às condições de vida e de saúde da população como um todo, expressando o número de anos de vida que se espera de um recém-nascido vivo. Podemos notar que, de 1950 a 2020, a esperança de vida ao nascer para ambos os sexos passou de 48 anos para 76,74 anos, um aumento de 32,57 anos de vida. E, chegará em 80,57 anos em 2050. Esse aumento pode ser observado ao longo dos anos. Mas, a diferença da expectativa de vida entre idosos e idosas permanece nos anos apresentados (cf. tabela abaixo). As mulheres vivem, em média, sete anos mais do que os homens e isso é uma constante contínua.

Tabela 3 - BRASIL - Expectativa de Vida ao Nascer - de 1950, 2000, 2020 e 2050

\begin{tabular}{c|c|c|c|c}
\hline Ano & Total & Homem & Mulher & $\begin{array}{c}\text { Diferença entre os } \\
\text { sexos (em anos) }\end{array}$ \\
\hline 1950 & 48,0 & 45,3 & 50,8 & 5,6 \\
2000 & 69,8 & 66,0 & 73,9 & 7,9 \\
2020 & 76,74 & 73,26 & 80,25 & 6,99 \\
2050 & 80,57 & 77,37 & 83,81 & 6,44 \\
\hline
\end{tabular}

Fonte: IBGE, Censo Demográfico de 2010 e IBGE Projeções

Conforme Almeida et all (2015), a percepção da velhice por parte de mulheres pode revelar aspectos positivos e negativos. Entre os aspectos positivos, destaca que a velhice pode ser vista como uma etapa de maior participação social. Por outro lado, como pontos negativos, as idosas vivenciam situações limitadoras de sua idade e de uma geração vivenciada como o preconceito social, a baixa escolaridade, os problemas familiares, as carências afetivas, a dependência financeira, a solidão, a viuvez, presença de doenças crônicas. Situações essas que, condizente com os autores, podem estar colocando as mulheres idosas em situação de maior risco social.

Marly de Jesus Sá Dias e Jacira Serra (2018), por exemplo, estudam a imbricação entre mulheres, velhice e solidão, apontando a formação de uma "nova tríade" no Brasil hoje. Essa solidão seria decorrência de uma vida vivida em função de outras pessoas e que convive, na velhice, por diversas razões, com o afastamento dessas pessoas. O fato de vivermos numa sociedade que exalta a juventude e remete à imagem de velhas e velhos como improdutivos, rabugentos, etc. vai potencializar a uma imagem negativa do envelhecimento. As autoras acrescentam essa dimensão na discussão acerca da feminização do envelhecimento que faz com que seja elevado o número de mulheres idosas sem cônjuges (DIAS; SERRA, 2018). As autoras apontam também uma questão cultural extremamente presente em nossa sociedade: é aceito com mais naturalidade um homem casar com uma mulher mais nova, do que o inverso, ou seja, uma mulher se casando com um homem mais novo. Infelizmente, como apontam essas autoras, "O aumento progressivo da expectativa de vida e o número de idosos que envelhecem juntos não crescem na mesma proporção, seja pelo número de separações e divórcios na idade adulta, seja 
pela preferência já destacada dos homens idosos por companhia de mulheres mais jovens ${ }^{12}$ " (DIAS e SERRA, 2018, p. 23).

Para Baldin et all (2008), diversas são as perdas vivenciadas na velhice, mas a perda de um companheiro traz consigo mudanças comportamentais que podem ser inesperadas no cotidiano, na família, na sociedade por parte da idosa viúva. Ou pode abrir outros horizontes para muitas mulheres, agora liberadas da figura masculina (seja do pai, seja do marido). Nesse sentido, é importante destacar que o fato de morarem sozinhas não significa necessariamente a solidão e o abandono, como bem destacam essas autoras. O fato de morar só pode ser também uma opção e para algumas, a vivência de uma liberdade que não tinham acesso antes ao estarem casadas e vivendo uma vida muito marcada pelos papeis de gênero.

Em suma, de acordo com os dados apresentados, podemos notar que está acontecendo o envelhecimento da população brasileira. E, nessa transição demográfica e etária, as mulheres idosas ganham destaque e assinalam que o envelhecimento populacional brasileiro precisa ser analisado de forma interseccional. Para garantir uma cidadania plena às idosas, temos que nos perguntar como as mulheres estão envelhecendo? Quem é essa mulher que envelhece? Que demandas elas colocam para a saúde?

\section{Saúde e população idosa - refletindo algumas dimensões}

Como podemos observar, o prolongamento da vida da população brasileira é fato presente e que se intensificará nos próximos anos. Partimos da compreensão de que o envelhecimento envolve aspectos biológicos, psicológicos, econômicos, políticos, familiares, sociais, sexualidades, entre outras dimensões que fazem parte do ciclo de vida de cada idosa/o na sociedade que vivemos (CAMARANO \& PASINATO, 2004). Logo, o conceito idosa/o deve ser compreendido de forma mais ampla do que apresentado pelo determinismo biológico e/ou cronológico que estabelece a velhice focada no indivíduo isolado e no tempo de vida vivido. Isso importa para que as ações e políticas voltadas para o envelhecimento possam levar em consideração a autonomia, participação, cuidado e satisfação pessoal de cada um. Conforme Barreto, Carreira e Marcon (2015, p. 326)

Qualquer política destinada aos idosos deve considerar sua capacidade funcional, necessidade de autonomia, participação, cuidado e autosatisfação. Também deve abrir campo para possibilidade de atuação em variados contextos sociais e de elaboração de novos significados para a vida na idade avançada. E ainda incentivar, fundamentalmente, a prevenção, o cuidado e a atenção integral à saúde das pessoas idosas.

O envelhecimento populacional traz consigo muitos desafios. Como afirma Freitas (2017), o discurso médico vai enfatizar as diferenças biológicas entre as mulheres e os homens para a definição de seus papeis sociais e, em relação às mulheres, sempre esteve mais voltado para a dimensão da saúde reprodutiva - a chamada "matriz" (o útero) foi considerada, por muitos anos, o estudo fundamental na hora de pensar o corpo feminino (NUNES, 1991) - mas

\footnotetext{
12 Isso é confirmado também pelo estudo de Baldin et all (2008, p. 44): “os diferenciais por sexo quanto ao estado conjugal devem-se à maior longevidade das mulheres e ao fato da prevalência da cultura de os homens se casarem novamente e com mulheres mais jovens".
} 
como fica essa dimensão em relação à mulher idosa, que está fora da saúde reprodutiva? O conhecimento médico pautado em representações consideradas universais acaba por apontar o masculino travestido de universalidade. As representações construídas socialmente é que dão direção às teorias e práticas médicas. Para as mulheres, a maternidade surge como destino inexorável. Já para os homens, a virilidade é o elemento que o caracterizará. Disso resulta uma visão determinista do que seria a "natureza" feminina (predisposta a histeria, volúvel, frágil e cujo corpo era talhado para a maternidade) e a "natureza" masculina (forte, viril, racional, talhado para o trabalho e as responsabilidades). Dessa equação, temos a definição dos papeis materno e paterno, fazendo com que qualquer outro papel assumido pelas pessoas em suas vidas fosse visto como desviante e passível de tratamento (FREITAS, 2017).

A saúde da mulher, principalmente em decorrência dos movimentos feministas, vem sendo alvo de discussões desde os anos de 1980. Mas não podemos negar que, ainda hoje, ao se falar em saúde da mulher é a saúde reprodutiva que nos vem a mente. E as mulheres idosas? O que se tem de específico para esse público? Para Lima e Bueno (2009), sabe-se pouco a respeito da sexualidade feminina na terceira idade, inclusive sobre a homossexualidade feminina. É como se, de repente, a mulher, nesta faixa de idade, se tornasse invisível, não merecendo mais a atenção da sociedade e tampouco o interesse acadêmico e profissional das diversas áreas.

Não se pode negar os avanços existentes em relação à proteção social de idosas e idosos no Brasil. A década de 1980 foi rica no que se refere às movimentações sociais ${ }^{13}$. Em 1982, foi realizada a I Assembleia Mundial sobre o Envelhecimento (ONU), em Viena, que traçou as diretrizes para o Plano de Ação Mundial sobre o Envelhecimento, aprovado em Nova York, no ano de 1983. No Brasil, em 1986, tivemos a realização da histórica $8^{a}$ Conferência Nacional de Saúde onde houve a elaboração de uma nova concepção de saúde e atendimento universal e integral que contribuiu para o texto legal da Constituição Federal de 1988. A Constituição Brasileira de 1988 defende a concepção ampliada de saúde, enquanto direito de cidadania: "A saúde é direito de todos e dever do Estado, garantido mediante políticas sociais e econômicas que visem à redução do risco de doença e de outros agravos e ao acesso universal e igualitário às ações e serviços". A Constituição coloca a saúde como um direito de todos e obriga o Estado na promoção e execução de políticas na área. Além disso, a família, a sociedade e o Estado têm o dever de amparar a saúde a população idosa ${ }^{14}$. A Constituição é o primeiro reflexo no que se refere às mudanças radicais da visão do envelhecimento no país.

$\mathrm{Na}$ década de 1990, diversos avanços legais e normativos aconteceram na ampliação da proteção social voltada para a população idosa brasileira. Em 1993, a aprovação da Lei Orgânica de Assistência Social (LOAS) passou a garantir direitos a esse seguimento com a criação do Benefício de Prestação Continuada (BPC). O BPC possibilitou o acesso de um salário mínimo mensal à pessoa portadora de deficiência e a/ao idosa/o, desde que necessitem deste benefício. Em 1994, foi aprovada a Lei No 8.842/1994 que estabeleceu a Política Nacional do Idoso (PNI) visando a "assegurar os direitos sociais do idoso, criando condições para promover sua autonomia, integração e participação efetiva na sociedade". Em 1996, houve a criação do Conselho Nacional do Idoso cujo objetivo foi assegurar a autonomia, integração e a participação

\footnotetext{
13 Esse pequeno histórico foi construído com base em Fernandes e Soares (2012) e Lins e Andrade (2018).

14 Contudo, essa responsabilidade não pode ser encarada como se esses três sujeitos tivessem a mesma capacidade de proteção. O que terminamos por ver é a sobrecarga em cima das famílias como principais responsáveis pela proteção a seus idosos. Cf, neste sentido o interessante livro organizado por Mioto, Campos e Carloto (2015).
} 
efetiva do idoso na sociedade. Em 2003, entra em vigor, a Lei no 10.741 que aprova o Estatuto do Idoso, um dos principais marcos no acesso aos direitos dos idosos.

Em relação à saúde, em 1999, ocorreu a implantação da Política Nacional da Saúde do Idoso pela Portaria 1.395/1999 do Ministério da Saúde (MS). Entre suas diretrizes busca-se a promoção do envelhecimento saudável, a prevenção de doenças, a manutenção da capacidade funcional, a assistência às necessidades de saúde dos idosos, capacitação de recursos humanos, o apoio ao desenvolvimento de cuidados informais e o apoio aos estudos e pesquisas voltados a esse segmento.

No que se referem aos debates internacionais, foram realizados os seguintes eventos: em 2002, aconteceu a Segunda Assembleia Mundial sobre Envelhecimento, em Madrid; em 2003, foi realizada a Conferência Regional Intergovernamental sobre Envelhecimento da América Latina e Caribe, no Chile; em 2006, foi realizada I Conferência Nacional dos Direitos da Pessoa Idosa no Brasil. A I Conferência aprovou “[...] diversas deliberações, divididas em eixos temáticos, que visou garantir e ampliar os direitos da pessoa idosa e construir a Rede Nacional de Proteção e Defesa da Pessoa Idosa - RENADI" (FERNANDES e SOARES, 2012, p. 1497).

Lins e Andrade (2018) ao analisarem as conferências de mulheres e de idosos ${ }^{15}$, apontam que, de maneira geral, a preocupação central nesses documentos é "remediar doenças já instaladas e demandar a atuação do Estado em relação a estas mulheres". Não existe o entendimento da saúde das mulheres idosas envolvendo alimentação, esporte ou lazer; ao contrário, "relaciona-se, sobremaneira, o período do climatério e menopausa às mulheres idosas e à necessidade de que recebam acompanhamento médico e hormonal para tanto". Aponta, contudo, que nas conferências, "o cuidado com a alimentação, a realização de atividades físicas regulares e uma vida sexual prazerosa também aparecem como fatores que influenciam uma vida saudável" (LINS e ANDRADE, 2018 - 453). As autoras concluem que "em geral, identifica-se uma certa ausência de propostas de ações para garantir um envelhecimento saudável, um conceito positivo e ativo de envelhecimento, orientado ao desenvolvimento econômico e social das mulheres idosas (LINS e ANDRADE, 2018, p. 456).

Reafirmando a histórica crítica feita pelo feminismo, o que se assiste é a invisibilização das mulheres e a ausência das questões específicas que só podem ser acessadas quando nos debruçamos na realidade concreta vivida por essas mulheres. Temos instalado aqui o perigo de um olhar muito geral e universal que busca incluir todas, mas que exatamente por conta disso, termina por não dá conta das especificidades ${ }^{16}$. Podemos aproximar essas reflexões daquelas estabelecidas por Crenshaw (2002) no conceito de superinclusão. Ou seja, ao se falar num

\footnotetext{
15 Segundo essas autoras, "em grande medida, podemos dizer que o enquadramento dado às mulheres idosas nos resultados dos processos conferencistas nacionais aqui analisados é o da ausência. Contudo, é preciso considerar que pode estar ocorrendo um esvaziamento da construção de propostas específicas para esse grupo populacional nos processos conferencistas com a fragmentação em outras questões. Isto pode ocorrer tanto em função da pouca força deste segmento nos movimentos feministas, quanto como uma estratégia das conferencistas no sentido de universalização das pautas para que ocorra maior inclusão de mulheres" (LINS e ANDRADE, 2018, p. 460).

16 "Por outro lado, é também com base no processo de inclusão de diferentes temáticas e grupos num mesmo bojo de políticas públicas, em que podem ocorrer os maiores apagamentos das próprias pautas e desconsideração das especificidades de determinados grupos. Existe a necessidade de que muitos destes grupos tenham direito a políticas afirmativas específicas para poderem sair da situação de exclusão e marginalização que vivenciam. Em outras palavras, quando se opta pela abordagem universalista, demandas específicas dos grupos acabam sendo invisibilizadas e não abordadas nas políticas. É uma estratégia de inclusão - a universalização de todas as pautas de mulheres - mas que oferece riscos em sua implementação" (LINS e ANDRADE, 2018, p. 457).
} 
universal abstrato, desconsidera-se questões e problemas que atingem grupos específicos, o que resulta na dificuldade de se traçar estratégias ${ }^{17}$.

Nos detendo especificamente na dimensão da saúde da mulher idosa, Lins e Andrade (2018) ressaltam que estas acumulam importantes desvantagens, como "violência, discriminação, salários inferiores aos dos homens, baixa escolaridade, dupla jornada de trabalho ou dedicação exclusiva do cuidado do lar e dos filhos, situação socioeconômica desvantajosa e consequente dependência de recursos" (LINS; ANDRADE, 2018, p. 441). Por isso, a importância de pensar e formular propostas, como apontado por essas autoras, que vá além da visão tradicional dos cuidados em saúde, para abordar igualmente questões relacionadas ao acesso à renda mínima, à educação, ao lazer. Isso é ainda mais oportuno se pensarmos em termos de uma concepção ampliada de saúde e de cidadania.

As políticas públicas direcionadas às mulheres e às pessoas idosas ainda são permeadas por questões retrógradas, que visam apenas a saúde, em função do adoecimento pela velhice, de forma a pouco evidenciar os demais direitos humanos desta população, formas de participação política, questões de geração de renda e emprego, entre outros. Assim, a situação das mulheres idosas continua silenciada mesmo em documentos e políticas que deveriam almejar e ampliar formas mais democráticas para todas as mulheres (LINS e ANDRADE, 2018, p. 444).

Outra discussão atual diz respeito ao direito a acompanhante pelas pessoas idosas. Essa questão nos remete necessariamente à economia do cuidado. São as mulheres que normalmente ocupam esse papel. Mulheres pobres, mulheres negras e muitas mulheres idosas se ocupam do cuidar de seus netos, filhos e maridos. Não é incomum mulheres de 60 anos cuidando de suas mães que tem 80. O envelhecimento populacional demanda cuidados e quando o Estado não oferece, esse tem que ser buscado nas redes estabelecidas na comunidade próxima - o que acaba por onerar ainda mais as mulheres, especialmente as mulheres negras e pobres. Mulheres idosas necessitando de cuidados, mas que também são cuidadoras (LINS e ANDRADE, 2018). Por isso, a análise das relações de gênero não pode ser desconsiderada ao se olhar a velhice, pois uma dupla discriminação acontece em relação às mulheres idosas: por serem mulheres e idosas. Pensar na saúde das idosas implica conhecer quem são essas idosas e suas demandas específicas. Quais são, por exemplo, na saúde as reivindicações das travestis e mulheres trans que envelhecem? Fala-se num envelhecimento saudável, mas o que isso significa para indígenas idosas? Para mulheres deficientizadas?

Tavares et all (2017), em seu estudo sobre a saúde das idosas de baixa renda, enfatiza a importância da "reciprocidade no apoio social entre as mulheres idosas de baixa renda e sua rede social”. Essas autoras sinalizam que a produção científica sobre mulheres idosas de baixa renda destaca as doenças crônicas não transmissíveis, como a hipertensão, um dos desafios a serem enfrentados na construção de uma política de saúde para essa população. Ainda, nesta pesquisa,

17 Esta autora também traz a noção de subinclusão, que foca numa questão específica e não dá conta de entender como determinada questão se refere a realidades que atingem diferentes grupos: "em resumo, nas abordagens subinclusivas da discriminação, a diferença torna invisível um conjunto de problemas; enquanto, em abordagens superinclusivas, a própria diferença é invisível" (CRENSHAW, 2002, P. 176). Crenshaw (2002) traz como exemplo de superinclusão o tráfico de mulheres. Fala-se em programas para o tráfico, mas muitas vezes se desconsidera o modo como ele atinge grupos específicos, como as mulheres negras e pobres. Já para a noção de subinclusão ela aponta o exemplo da esterilização das mulheres pobres, descartando o conteúdo racial. 
as autoras (e outras citadas por estas), concordam que as idosas no enfrentamento dessas doenças tem como estratégia o apoio dos familiares. A conclusão dessas estudiosas é que é fundamental que a assistência à saúde da mulher idosa "ultrapasse as questões medicamentosas e inerentes a mudança de estilo de vida e considere também a subjetividade e sua cultura" (TAVARES et all, 2017, p. 917). Deste modo, consideram essencial envolver a família e/ou pessoas da rede social para apoiar no cuidado à saúde. O que reafirma a relevância das redes sociais em todos os estudos acerca das famílias no Brasil (SARTI, 2003; FONSECA, 2002; FREITAS, 2000; FREITAS, BRAGA e BARROS, 2010). Nessa lógica, quando a idosa recebe o apoio social, apresenta menos chances de adoecer, o que contribui para a melhoria da sua qualidade de vida (TAVARES, 2017). Afinal - não por uma questão natural, mas socialmente construída - as mulheres estabeleceram redes sociais como estratégias de vida e isso acontece mais entre mulheres do que entre os homens.

Sinalizamos assim algumas questões que precisam ser melhor problematizadas. No quesito classe social, essa questão é ratificada com as mulheres idosas de baixa renda, residentes em comunidades carentes da cidade do Rio de Janeiro, ganham destaque por dar suporte financeiro e cuidar de seus netos para que suas/seus filhas/os possam exercer as atividades laborais. Então, as idosas e idosos contribuem financeiramente para a renda familiar, com sua aposentadoria, ou cuidam dos netos para que os filhos possam exercer as atividades laborais - e essa atividade esteve historicamente nas mãos das mulheres.

Outro ponto a destacar diz respeito à rotina institucional. Por exemplo, podemos nos referir aos horários de funcionamento dos hospitais ou postos de saúde. Tais horários são pensados, geralmente, a partir de um referencial de família de camadas médias onde a mulher não trabalhava fora. São horários de visita em que os homens e mulheres que trabalham não podem ir, ou se vão, correm o risco de perder o emprego. Visitas noturnas para que filhos possam ver seus pais internados pode ser um bom começo. Horários mais flexíveis que possibilitem a ampliação das possibilidades de visita é também uma maneira de melhorar as relações dentro dos hospitais. E, possibilitar a maior participação dos homens nesse processo.

Outra dimensão considerável é o compromisso das políticas em não onerar as mulheres e suas famílias. A responsabilidade do envelhecimento não pode ser unicamente das famílias, o que parece apontar a perspectiva familista cada vez mais em vigor, no Brasil, e que é uma faceta de longa tradição histórica em nossa sociedade (MIOTO, CAMPOS e CARLOTO, 2015). Nossas/os velhas/os não podem ser responsabilidade apenas das famílias.

Da mesma forma, o meio ambiente merece atenção, pois o local onde se vive pode contribuir para a dependência, falta de autonomia e isolamento social. Segundo Tavares (2017), uma pesquisa realizada com idosos poloneses verificou que, para ter qualidade de vida elevada, é necessário ter boa educação e renda suficiente para viver. Temos aqui, além da dimensão do gênero, a da classe e a territorial como fundamentais.

Assim sendo, para a população idosa, a saúde não se restringe apenas ao controle e à prevenção de agravos de doenças crônicas não transmissíveis, mas também à interação entre a saúde física e mental, a independência financeira, a capacidade funcional e o suporte social (FERNANDES; SOARES, 2012). Cabe enfatizar que muitas são as políticas focalizadas nos idosos, porém, as dificuldades na implementação abrangem desde a captação precária de recursos ao frágil sistema de informação para a análise das condições de vida e de saúde, como também a capacitação inadequada de recursos humanos. A equipe de atenção às idosas merece prioridade nessas reflexões. 
Motta e Aguiar (2007) abordam as novas competências profissionais na área da saúde voltadas a pensar o envelhecimento populacional brasileiro. Seu estudo discute as características da formação médica frente ao processo de envelhecimento e as especificidades da atenção à saúde do idoso. Suas conclusões podem ser uteis para pensar não apenas a medicina, mas os diversos profissionais que compõem a equipe de saúde. Concordamos com essas autoras ao afirmarem que há uma distância entre os conteúdos necessários à boa prática geriátrica e os currículos de graduação e da pós-graduação. Não podemos deixar de aproximar essa discussão para a formação profissional da assistente social. Para Motta e Aguiar (2007, p. 363),

A inclusão do processo de envelhecimento como curso de vida e em todos os seus aspectos nos currículos de graduação é uma prioridade. É também necessário ampliar a discussão sobre o papel da pós-graduação, da educação permanente e da educação continuada a fim de fazer frente ao desafio de envelhecer com qualidade.

As autoras refutam a necessidade de avançar na direção da interdisciplinaridade na formação em saúde e na intersetorialidade das ações e políticas públicas. O mesmo vale para pensar além da integralidade, da intersetorialidade, da interdisciplinaridade e da interseccionalidade que defendemos na garantia de um envelhecimento saudável ${ }^{18}$.

\section{Considerações finais - Dilemas e Desafios}

Ao analisar o processo de envelhecimento da população brasileira, na cena contemporânea, constata-se que o processo de envelhecimento da sociedade brasileira tem sido acompanhado pelo processo de feminização da velhice. Isso nos diz muito acerca desse processo, mas não nos diz tudo. É preciso complexificar a noção da velhice e compreender os diferentes sujeitos que compõem esse seguimento populacional. Pensar de forma homogênea nos impossibilita de conhecê-los e, então, assegurar uma intervenção que vá ao encontro as demandas e desejos postos.

Em consonância com o que Bassil (2002) coloca, compreender a velhice apenas a partir das noções de perdas e limitações compromete o entendimento de uma velhice vivida de formas distintas. Desse modo, estudar o processo de envelhecimento na perspectiva de diferentes cursos de vida permite ampliar nossos referenciais de análise, tanto para o conhecimento dos problemas existentes como para a delimitação e análise de novos problemas de investigação. Bassil (2002) sinaliza - e nos parece bem interessante essa perspectiva - a utilização de histórias de vida ${ }^{19}$ e depoimentos de pessoas como uma forma de apreender como as pessoas vivem "o seu próprio envelhecimento", tendo em conta que esse processo se dá a partir de diferentes contextos sociais, culturais e históricos. Ou seja, trata-se de tentar compreender o envelhecimento a partir da perspectiva daqueles que estão envelhecendo. Esse é um caminho que nos parece sedutor. É essencial ouvir esses relatos para mostrar como, por pertencerem a diferentes grupos sociais, as trajetórias de vida foram influenciadas de forma distinta pelo mesmo conjunto de eventos históricos e culturais (BASSIL, 2002). A partir dessas vivências, queremos enfatizar, os diferentes

18 "O envelhecimento saudável é assim entendido como a interação entre saúde física e mental, independência nas atividades de vida diária (capacidade de vestir-se, tomar banho, fazer higiene, transferir-se, alimentar-se, ser continente), integração social, suporte familiar e independência econômica". (MOTTA e AGUIAR, 2007, p. 364)

19 Não podemos esquecer a relação academicamente tecida entre os estudos de mulheres e a metodologia da história oral. 
marcadores sociais que o instrumental da interseccionalidade nos permite aproximar: as questões de classe, gênero, raça, geração, sexualidade, territorialidade e outros.

Na obra "A Velhice" (1990), Simone de Beauvoir mostra que as condições de vida dos idosos eram objeto de estudo de diversas sociedades antigas, sendo a velhice compreendida como um processo dinâmico, resultado do prolongamento da vida. A autora parte de inúmeros questionamentos sobre a velhice: “o que é envelhecer?" "Em que consiste o processo de envelhecimento?". Tais reflexões nos leva a conclusão de que se trata de uma realidade que não é fácil de definir e que estamos falando de um fenômeno que é biológico, mas também cultural, pois "a velhice não poderia ser compreendida senão em sua totalidade; ela não é somente um fato biológico, mas também um fato cultural” (BEAUVOIR, 1990, p. 16).

Como afirmamos, uma característica própria da perspectiva feminista é compromisso com a justiça social. Ao possibilitar a identificação dessas diversas dimensões, compreendemos a interseccionalidade como ferramenta imprescindível para a elaboração e implementação da política social ${ }^{20}$ e consolidação da cidadania. Como afirmam Freitas, Mesquita e Silva (2020, p. 67):

Partimos de uma concepção ampliada que dê conta não apenas da esfera social, política e civil, mas também englobando os direitos sexuais, humanos, culturais, epistemológicos, etc.; direitos estes fundamentais para que se tenha uma cidadania que permita a vivência nos seus mais diferentes domínios.

Pensando especificamente na área da saúde, mais do que nunca compreendemos a necessidade de uma escuta - atenta e qualificada - para lidar com nossas idosas e idosos. Sair de uma noção da velhice como sinônimo de perda e de uma visão homogênea para se pensar a construção de políticas públicas na área social - e da intervenção - que contemple a escuta e as demandas específicas dessas mulheres, de modo mais específico, e homens que envelhecem.

\section{Referências:}

ALMEIDA, Alessandra Vieira et all. A Feminização da Velhice: em foco as características socioeconômicas, pessoais e familiares das idosas e o risco social. Revista Textos \& Contextos (Porto Alegre), v. 14, n. 1, p. 115 - 131, jan./jun. 2015.

ALMEIDA, Magali da S. Diversidade humana e racismo: notas para um debate radical no serviço social. Revista Argumentum, v. 9, n.1, p.32-45; jan, 2017.

BALDIN, Carla Borsoi; FORTES, V. L. F. Viuvez feminina: a fala de um grupo de idosas. Revista Brasileira da Ciência do Envelhecimento Humano - RBCEH, Passo Fundo, v. 5, n. 1, p. 43-54, jan./jun. 2008.

BARRETO, M. da S., CARREIRA, L., \& MARCON, S. S. Envelhecimento populacional e doenças crônicas: Reflexões sobre os desafios para o Sistema de Saúde Pública. Revista Kairós

${ }^{20}$ Entendida aqui como resultante das relações entre Estado, Mercado e Sociedade. Ver neste sentido Pereira (2004 e 2020). 
Gerontologia, FACHS/NEPE/PEPGG/PUC-SP, São Paulo v.18, n.1, p. 325-339. janeiromarço 2015.

BASSIL, Ana Zahira. Histórias de Mulheres: reflexões sobre a maturidade e a velhice, In: Antropologia, saúde e envelhecimento (Organizado por Maria Cecília de Souza Minayo e Carlos E. A. Coimbra Jr). Rio de Janeiro: Editora FIOCRUZ, 2002. 212p.

BEAUVOIR, Simone de. A velhice. Rio de Janeiro: Nova Fronteira, 1990.

BRASIL. Constituição Federal de 1988.

BRASIL. Estatuto do Idoso - Lei N. 10.741/2003.

BRASIL. Lei Orgânica da Assistência Social - LOAS, n. 8.742 de 1993.

BRASIL. Política Nacional do Idoso - PNI, Lei N. 8.842/199.

CAMARANO, A. M.; KANSO, S.; MELLO, J. L. Como vive o idoso brasileiro. In:

CAMARANO, A (Org.). Os novos idosos brasileiros: muito além dos 60? Rio de Janeiro: IPEA, 2004, p. 25-73.

CARNEIRO, Sueli. Mulheres em movimento. Estudos Avançados., São Paulo, v. 17, n. 49, pág. 117-133, dezembro de 2003.

COLLINS, Patricia Hil. "Em direção a uma nova visão: raça, classe e gênero como categorias de análise e conexão", Reflexões e práticas de transformação feminista (org. Renata Moreno), SOF (Coleção Cadernos Sempreviva), 2015.

CRENSHAW, Kimberlé. "Documento para encontro de especialistas em aspectos da discriminação racial relativos ao gênero", Revista Estudos Feministas, ano 10, Florianópolis, 2002.

CURIEL, Ochy. "Entrevista: Ochy Curiel e o feminismo decolonial” (Entrevista feita por Ana Paula Procópio da Silva, Magali da Silva Almeida e Renata Gonçalves). Revista Em Pauta, n. 46, v. 18, 2020, p. $269-277$.

DIAS, Marly de Jesus Sá e SERRA, Jacira. Mulher, velhice e solidão: Uma tríade contemporânea? Revista Serviço Social \& Saúde, Campinas, SP v. 17 n. 1 [25] p. 9-30 jan./jun. 2018.

FERNANDES, Maria Teresinha de Oliveira e SOARES, Sônia Maria. O desenvolvimento de políticas públicas de atenção ao idoso no Brasil. Revista Escola de Enfermagem da USP, n. 46 (6), 2012.

FONSECA, Cláudia. Mãe é uma só? Reflexões em torno de alguns casos brasileiros, Revista Psicologia USP, n. 2, v. 13, São Paulo: USP-IP, 2002. 
FREITAS, Rita de Cássia Santos. "Mães de Acari: Preparando a tinta e revirando a praça: um estudo sobre mães que lutam”. Tese de Doutorado apresentada ao Programa de Pós-Graduação da Escola de Serviço Social da Universidade Federal do Rio de Janeiro, 2000.

FREITAS, Rita de Cássia Santos; MESQUITA, Adriana de Andrade e SILVA, Glauber Lucas Ceará. Política Social, Famílias e Relações de Gênero: Reflexões e Proposições. In: SENNA, Mônica; FREITAS, Rita e MORAES, Carlos (org.), Cidadania e Política Social no Brasil, Rio de Janeiro: Ed. CRV, 2020.

FREITAS, Rita. “A construção socialdos papéis de gênero na família e as (nossas) práticas em saúde. In Teresa Kleba Lisboa et all (org.). Estudos interdisciplinares sobre gênero, família e saúde. Tubarão, Santa Catarina: Copiart, 2017.

FREITAS, Rita; BRAGA, Cenira; BARROS, Nívia. Família e Serviço social - Algumas reflexões para o Debate. In: DUARTE, et al. (Org.) Família e Famílias: práticas sociais e conversações contemporâneas, Rio de Janeiro. Lumen Juris. 2010.

INSTITUTO BRASILEIRO DE GEOGRAFIA E ESTATÍSTICA. Disponível em: https://www.ibge.gov.br/apps/populacao/projecao/index.html. Acesso em: 15 jun. 2021.

KALACHE, Alexandre. Envelhecimento Populacional: uma realidade brasileira. Revista Saúde Pública, São Paulo, 21(3), 211-224, 1987.

KETZER, Patricia. "Como pensar uma Epistemologia Feminista? Surgimento, repercussões e problematizações”. Revista Argumentos, ano 9, n. 18, Fortaleza, jul./dez. 2017.

KILOMBA. Grada. "DESCOLONIZANDO O CONHECIMENTO” Uma PalestraPerformance de Grada Kilomba. Disponível em: https://joaocamillopenna.files.wordpress.com/2018/05/kilomba-grada-ensinando-atransgredir.pdf. acesso em: 28 ago. 2020.

LAHNI, Cláudia Regina; AUAD, Daniela. Não é mole não, ser feminista, professora e sapatão: apontamentos de uma história a partir do espaço das lésbicas e da lesbianidade na produção de conhecimento sobre mídia. In.: PEDRO, Joana Maria; VERAS, Elias Ferreira. Lutas feministas e LGBtQ+ pela democracia no Brasil. Revista do Programa de Pós-Graduação em História. Universidade Federal do Rio Grande do Sul. Anos 90, Porto Alegre, v. 26, 2019.

LIMA, Lara Carvalho Vilela de e BUENO, Cléria Maria Lobo Bittar. Envelhecimento e gênero: a vulnerabilidade de idosas no Brasil. Revista Saúde e Pesquisa, v. 2, n. 2, p. 273-280, mai./ago. 2009.

LINS, Isabella Lourenço e ANDRADE, Luciana Vieira Rubim. A feminização da velhice: representação e silenciamento de demandas nos processos conferencistas de mulheres e pessoas idosas. Revista MEDIAÇÕES, Londrina, v. 23 n. 3, p.436-465, dez. 2018. 
LOURO, Guacira Lopes. "Uma epistemologia feminista”, Gênero, sexualidade e educação: uma perspectiva pós-estruturalista, 6. ed., Petrópolis: ed. Vozes, 1997.

MBEMBE, Achille. Necropolítica. 3. ed. São Paulo: n-1 edições, 2018.

MEDEIROS, Luciene e FREITAS, Rita. Por onde caminhamos até chegarmos aqui. Apresentação da Revista O Social em Questão, 2017.

MESQUITA, Adriana de Andrade. Envelhecimento Populacional e relações de gênero: velhos dilemas e novos desafios. In: Serviço Social, Formação Profissional e Política Social: questões contemporâneas. MESQUITA, A; ASSIS, J.; DUTRA, V. (Orgs.) - Rio de Janeiro: Gramma, 2018.

MIOTO, Regina Célia Tamaso; CAMPOS, Marta Silva e CARLOTO, Cássia Maria (org.). Familismo, direito e cidadania: contradições da política social. São Paulo: Cortez ed., 2015.

MORAES, Carlos Antonio de Souza; SANTOS, Cristiane Medeiros dos e GONÇALVES, Jefferson Ferraz. Particularidades do mercado de trabalho e do trabalho de assistentes sociais na política de saúde no Brasil. In: SENNA, Mônica; FREITAS, Rita e MORAES, Carlos (Orgs.), Cidadania e Política Social no Brasil, Rio de Janeiro: Ed. CRV, 2020.

MOTA, Luciana Branco da e AGUIAR, Adriana Cavalcanti de. Novas competências profissionais em saúde e o envelhecimento populacional brasileiro: integralidade, interdisciplinaridade e intersetorialidade. Revista Ciência \& Saúde Coletiva, 12(2):363-372, 2007.

MOTTA, Alda Britto da. "Envelhecimento e Sentimento do Corpo", In: Antropologia, saúde e envelhecimento In: MINAYO, Maria Cecília de Souza; COIMBRA JR., Carlos E. A. (Orgs.). Rio de Janeiro: Editora FIOCRUZ, 2002. 212p.

NERI, A. L. (2001). O fruto dá sementes: processos de amadurecimento e envelhecimento. In A. L. Neri (Org.), Maturidade e velhice: trajetórias individuais e socioculturais, Campinas: Papirus, 2001.

NICODEMO, D.; GODOI, M. P. Juventude dos anos 60-70 e envelhecimento: estudo de casos sobre feminização e direitos de mulheres idosas. Rev. Ciênc. Ext. v.6, n.1, p.40, 2010.

NUNES, Silvia Alexim. A medicina social e a questão feminina. Physis, n. 1, v. 1, Rio de Janeiro: IMS/UERJ; Relume-Dumará, 1991.

ONU. World Population Prospect 2019: highlights. United Nations - New York, 2019.

OYĚWÙMÍ, Oyèrónké. Conceituando o gênero: os fundamentos eurocêntricos dos conceitos feministas e o desafio das epistemologias africanas. Tradução de Juliana Araújo Lopes. Texto original: OYĚWÙMÍ, Oyèrónké. Conceptualizing Gender: The Eurocentric Foundations of 
Feminist Concepts and the challenge of African Epistemologies. African Gender Scholarship: Concepts, Methodologies and Paradigms. CODESRIA Gender Series. Volume 1, Dakar, CODESRIA, 2004. Disponível em: https:// filosofiaafricana.weebly.com/uploads/1/3/2/1/13213792/oy\%C3\%A8r\%C3\%B3nk\%C3\%A9_oy $\%$ C4 $\% 9 \mathrm{Bw} \% \mathrm{C} 3 \% \mathrm{~B} 9 \mathrm{~m} \% \mathrm{C} 3 \% \mathrm{AD}_{-}-$ _conceitualizando_o_g\%C3\%AAnero._os_fundamentos_euroc $\% \mathrm{C} 3 \% \mathrm{AAntrico}$ _dos_conceitos_ feministas_e_o_desafio_das_epistemologias_africanas.pdf. Acesso em: 15 jun. 2021.

PEREIRA, Potyara Amazoneida P. "Mudanças estruturais, política social e papel da família: crítica ao pluralismo de bem-estar", Política Social, Família e Juventude: uma questão de direitos (org. Mione Apolinário Sales et all.), São Paulo: Cortez, 2004.

PEREIRA, Potyara. A política social entre Deus e o diabo: determinações e funcionalidades do sistema capitalista. In: SENNA, Mônica; FREITAS, Rita e MORAES, Carlos (Orgs.), Cidadania e Política Social no Brasil, Rio de Janeiro: Ed. CRV, 2020.

RAGO, Margareth. "Epistemologia feminista, gênero e história". Pensamento feminista brasileiro: formação e contexto (org. ARRUDA, Heloisa Buarque de Hollanda), Rio de Janeiro: Bazar do Tempo, 2019.

SALGADO, Carmen Delia Sánchez. Mulher idosa: a feminização da velhice. Estud. interdiscip. envelhec., Porto Alegre, v. 4, p. 7-19, 2002.

SANTOS, Ana Cristina. Entre a academia e o activismo: Sociologia, estudos queer e movimento LGBT em Portugal. Revista Crítica de Ciências Sociais, Coimbra/Portugal, n. 76, p. 91-108, dez. 2006.

SARTI, Cynthia Andersen. A família como espelho: um estudo sobre a moral dos pobres, $2^{\mathrm{a}}$ ed., São Paulo: Cortez, 2003.

SCOTT, Joan. “Os usos e abusos do gênero”, Projeto História, São Paulo, n. 45, 2012.

SCOTTT, Joan. Gênero: uma categoria útil de análise histórica. Cadernos SOS Corpo. Recife, 1990.

TAVARES, Renata Evangelista et all. "Conhecimento produzido sobre a saúde das idosas de baixa renda: revisão integrativa”. Revista Brasileira de Enfermagem, n. 70(4), 2017. 